\title{
0979 IMPACT AND LESSONS LEARNED FROM THE FIRST 5 YEARS OF THE CHILD SAFETY ACTION PLAN (CSAP) INITIATIVE IN 26 COUNTRIES IN EUROPE
}

M MacKay*, J Vincenten Correspondence: European Child Safety Alliance, EuroSafe, P.O. Box 75169, Amsterdam 1070AD, Netherlands

\subsection{6/ip.2010.029215.979}

CSAP is a European initiative whose aim is to raise awareness of injury as the leading cause of death for children in Member States and increase commitment to the issue through the development of evidence-based government endorsed national child safety action plans. To support development of plans and increased capacity to support implementation, three main areas of activity have been undertaken: (1) development and public release of Child Safety Report Cards and profiles based on standardised indicators, (2) activities to encourage adoption, implementation and monitoring of evidence-based good practices and (3) activities to support Child Safety Action Plan development. Information on the impact and lessons learned to date have been collected and validated using various methods including analysis of country progress updates, specific reflection sessions and questionnaires. Impacts to date include national child safety action plans in nine countries where none existed previously, new or stronger links with government and between national partners, increased awareness of child injury issue and increased capacity to take action, increased multi-sectoral cooperation, collaboration and enhanced political commitment to the issue, and demonstrated value of report card indicators used in benchmarking progress. Lessons learned include the importance of: leadership and commitment, early and continued involvement of the right people, having good tools and 


\section{IP Safety 2010 abstracts}

resources to work with, public benchmarking of performance and progress and linking into existing political commitments. The Child Safety Action Plan provides a model for other areas of injury to consider for enabling a coordinated and comprehensive approach to injury reduction efforts. 